DOI 10.5216/ia.v46i2.67811

\title{
O COTIDIANO DE CRIANÇAS POMERANAS NA EDUCAÇÃO INFANTIL
}

\author{
MYRNA GOWER MADIA BERWALDT \\ Gabriela MedeIROS Nogueira \\ Universidade Federal do Rio Grande (FURG), Rio Grande, Rio Grande do Sul, Brasil
}

\begin{abstract}
Resumo: Este artigo apresenta dados de uma pesquisa que teve por objetivo conhecer como um grupo de crianças pomeranas vivenciou a cultura lúdica e enfrentou os desafios no cotidiano, em uma turma de nível II da Educação Infantil de uma escola de Ensino Fundamental, ao longo de 2019. A investigação foi realizada por meio da análise de documentos e da etnografia, tendo a sociologia da infância como referencial teórico. Dentre os resultados encontrados, observamos que a língua foi um fator impactante no processo de inserção na escola, pois dois terços das crianças falavam apenas a Língua Pomerana e um terço era bilíngue em português e pomerano. No decorrer do ano, a Língua Portuguesa foi prevalecendo, o que teve como consequência o silenciamento da Língua Pomerana, caracterizando uma relação de subordinação de uma cultura à outra.
\end{abstract}

Palavras-chave: Crianças e Infância. Comunidade Pomerana. Educação Infantil. Cultura Lúdica.

\section{INTRODUÇÃO}

Este trabalho apresenta dados de uma pesquisa realizada em 2019 sobre o cotidiano de 13 crianças de uma comunidade pomerana ${ }^{1}$, em uma turma de nível II da Educação Infantil. Essa turma é ofertada em uma escola municipal de Ensino Fundamental do campo, no interior do município de Canguçu-RS².

Por meio dos pressupostos da sociologia da infância, que tem a criança como ator social e histórico, pertencente à categoria geracional - a infância - com estatuto próprio (CORSARO, 1990, 2007, 2011; SARMENTO, 2003, 2008), buscamos conhecer como as crianças vivenciaram a cultura lúdica. Isto é, uma cultura produzida em interação com sujeitos em um contexto específico e com significados compartilhados (BROUGÈRE, 1998, 2008), de que forma enfrentaram os desafios como, por exemplo, a apropriação da Língua Portuguesa e das rotinas no espaço escolar ${ }^{3}$.

A pesquisa foi desenvolvida por meio da análise de documentos oficiais, como emenda constitucional, pareceres, resoluções e decretos em âmbito federal, estadual e municipal. Da mesma forma, por documentos produzidos pelos pesquisadores (fotografias, filmagens e anotações em diário de campo) e da etnografia (GEERTZ, 2008; COHN, 2005; OLIVEIRA, 2006). A inserção no campo empírico da pesquisa foi realizada nos meses de fevereiro, abril, junho, setembro e novembro de 2019, totalizando 26 dias de observação do turno de aula. A produção de dados, por meio de observações e 
escritas em Diário de Campo, focou nos aspectos da vida diária e nas práticas sociais cotidianas, contabilizando 44 páginas manuscritas.

O texto está organizado em três seções. Na primeira, contextualizamos a vinda dos pomeranos para o Brasil, abordando o cotidiano daqueles que vivem na Serra dos Tapes. Esta região do Rio Grande do Sul é formada pelos seguintes municípios: São Lourenço do Sul, Turuçu, Pelotas, Arroio do Padre, Canguçu, Capão do Leão e Morro Redondo. Discorremos sobre aspectos da sua cultura como, por exemplo, agricultura familiar, culinária, religião e língua. Na segunda seção, focamos nas situações vivenciadas pelas crianças no pátio da escola, evidenciando o modo de ser criança nesses momentos, destacando as brincadeiras, os diálogos e como elas se relacionavam com o espaço e com os pares. Na terceira seção, tratamos sobre as Línguas Portuguesa e Pomerana, considerando que as crianças participantes da pesquisa são falantes da Língua Pomerana, Língua Portuguesa e alguns utilizam as duas línguas. Observamos que a comunicação entre crianças e adultos na escola se deu, inicialmente, facilitada por gestos ou em pomerano. Conforme os meses foram passando, a Língua Portuguesa prevaleceu e o pomerano foi, muitas vezes, considerado como uma língua de desprestígio social (TRESSMANN, 2005).

Por fim, refletimos que o ingresso das crianças pomeranas na Educação Infantil, em uma escola de Ensino Fundamental do campo, promoveu mudanças significativas marcadas por rupturas e adaptação à rotina escolar. Percebemos que a substituição de uma língua pela outra não implicou somente na oralidade, mas também nos aspectos culturais e de valores que vão aos poucos sendo também substituídos.

\section{POVOS POMERANOS: CONTEXTUALIZAÇÃO INICIAL}

Em meados do século XIX, a Pomerânia encontrava-se sob domínio do Império Prussiano. A substituição do feudalismo pelo capitalismo intensificou problemas de ordem política, social e econômica, impulsionando o processo de imigração de vários povos (CUNHA, 2007). Já no século XX, após longo período de resistência contra a invasão da Província Pomerana, eles sucumbiram e abandonaram suas terras. Em seguida, com a II Guerra Mundial, praticamente todo território da Pomerânia foi anexado à Polônia, gerando a expulsão dos pomeranos que ainda habitavam o local, e intensificando também a emigração, inclusive para o Brasil. Com o início da Segunda Guerra, no Brasil o nacionalismo passou a ser intensificado pelo Governo Brasileiro, promovendo "um sentimento de antigermanismo na população nativa. Tudo que lembrava fatos ou pessoas não brasileiras passou a ser hostilizado" (SEIBEL, 2010, p. 253). Eram associados aos alemães todos os imigrantes com características culturais e de língua materna alemã, originários da Alemanha, Áustria ou Polônia (SEYFERTH, 1974), entre eles, os pomeranos. Com a promulgação dos decretos de leis do Governo Federal, práticas de repressão contra imigrantes teuto-brasileiros e seus descendentes foram intensificadas, e passaram a afetar drasticamente o modo de vida destes povos. "O objetivo era romper os laços culturais que os mantinham ligados aos seus países de origem, em prol da homogeneização da sociedade brasileira" (MARLOW, 2013, p. 123). A 
BERWALDT, M. G. M.; NOGUEIRA, G. M

associação dos imigrantes teuto-brasileiros ao nazismo gerou muitas perseguições, como:

\begin{abstract}
As incursões dos "captura soldota", uma espécie de bandoleiros com atribuições oficiais de "prender nazistas", terminaram molestando muitas famílias de agricultores. Alimentos eram requisitados, livros de culto religioso, bíblias e hinários escritos em língua alemã eram queimados em público, sob argumento de constituírem propaganda nazista. Mulheres eram molestadas e homens espancados. Tudo em nome da Lei e com um intenso fervor nacionalista. (SEIBEL 2010, p. 271-272).
\end{abstract}

Após a Segunda Guerra Mundial de 1945, com o Tratado de Potsdam ${ }^{4}$ (TRESSMANN, 2015), a Pomerânia foi suprimida do mapa europeu. A parte Oriental passou para o domínio da Polônia e a Pomerânia Ocidental passou a pertencer à Alemanha com o nome de Mecklenburg-Vorpommern, Mecklenburg (SILLER, 2011).

A assinatura do Tratado de Potsdam e a efetivação do capitalismo, que implementou a monocultura mecânica, substituindo os camponeses que se dedicavam à agricultura familiar, são fatores que desencadearam a expulsão desse povo de sua terra natal. Além disso, os pomeranos tiveram suas "casas e terras saqueadas, mulheres e filhas estupradas" (JACOB, 2007, p. 142). E neste processo, segundo Roelke, (1996, p. 38):

\begin{abstract}
Um milhão e oitocentos mil pomeranos orientais tiveram que deixar tudo para trás, como muitas vezes eram obrigados a saírem de uma hora para outra de suas propriedades, muitos só conseguiram salvar a roupa do corpo. Em torno de 500 mil morreram no caminho para a Pomerânia Ocidental e restantes da Alemanha. Famílias inteiras eram dizimadas.
\end{abstract}

A vinda desses povos para o Brasil coincidiu com interesses do Governo Brasileiro em ocupar terras ociosas para desenvolvimento de ações que favorecessem seus planos de expansão e defesa de fronteiras. Conforme Beiersdorf e Weiduschadt (2013, p. 06),

O Governo Imperial tinha por necessidade o povoamento de regiões inóspitas, como a da Serra dos Tapes, no sul do Rio Grande do Sul. Isto se dava tanto pela sua ocupação humana, como pelo fato de toda a província de São Pedro do Rio Grande, também ser uma área de disputas fronteiriças com a Argentina e o Uruguai. Assim foi promulgada no ano de 1850 a Repartição de Terras Públicas, da qual se estabeleceu as normas e condições para aquisição de terras pertencentes ao Estado para a introdução da agricultura.

Por meio dessa movimentação, diferentes municípios do Rio Grande do Sul foram ocupados por imigrantes pomeranos, mas eles encontraram uma realidade diferente da que havia sido prometida ${ }^{5}$. As dificuldades perpassavam os costumes e as 
barreiras eram agravadas pela diferença linguística e pelo descaso das autoridades locais para com os imigrantes. As empresas responsáveis pela colonização, como a de Jacob Rheingantz, tinham como foco o lucro e as terras designadas aos imigrantes eram adquiridas por baixo valor, porém com divulgação de venda que promoviam grande procura (BEIERSDORF; WEIDUSCHADT, 2013). Desta forma, a imigração pomerana para o Brasil foi resultado, principalmente, de interesse econômico, possibilitando grande lucratividade para os envolvidos no processo da imigração.

Os pomeranos que emigraram para o Brasil exerciam atividades agrícolas na sua região de origem, pois no território que habitavam na Alemanha a agricultura era substancial na economia. No entanto, os pequenos camponeses tinham vínculos com os "barões", que eram os proprietários das terras, e sua produção era destinada a eles. No Brasil, as atividades agrícolas foram mantidas, apesar dos deveres de cumprimento de acordos firmados com o Governo Imperial, eles passaram a ter a posse da terra (SALAMONI, 1995).

\section{OS POMERANOS NA SERRA DOS TAPES}

Até meados do século XVIII, o território denominado Serra dos Tapes era uma vasta área coberta de matas, povoado somente por determinados grupos indígenas e a economia era organizada por meio da caça e da pesca (ARRIADA, 1994).

Para Cerqueira (2010), a paisagem cultural do território resulta de um mosaico étnico, fundamentado por memórias e tradições de grupos que constantemente sofreram processos de renovação e acomodação, em um permanente processo de diálogos culturais, travados entre as etnias do espaço colonial (italianos, alemães, pomeranos, franceses), bem como com o componente afro e luso-brasileiro. Os pomeranos que vivem na Serra dos Tapes caracterizam-se como um povo camponês que se dedica ao desenvolvimento da agricultura familiar, procura manter os ritos sociais e a língua materna no seu cotidiano. Na atualidade, esse grupo cultural é reconhecido no Brasil como pertencentes ao segmento de Povos e Comunidades Tradicionais $^{6}$.

O território Serra dos Tapes abriga os municípios gaúchos: São Lourenço do Sul, Turuçu, Pelotas, Arroio do Padre, Capão do Leão e Morro Redondo e Canguçu, município da pesquisa. Canguçu está localizado a 300 quilômetros de distância de Porto Alegre, capital gaúcha. Conforme é possível identificar no mapa abaixo, Canguçu-RS está dividido em distritos. A escola onde a pesquisa foi realizada se localiza no segundo distrito. 
Figura 1: Mapa do Município de Canguçu-RS

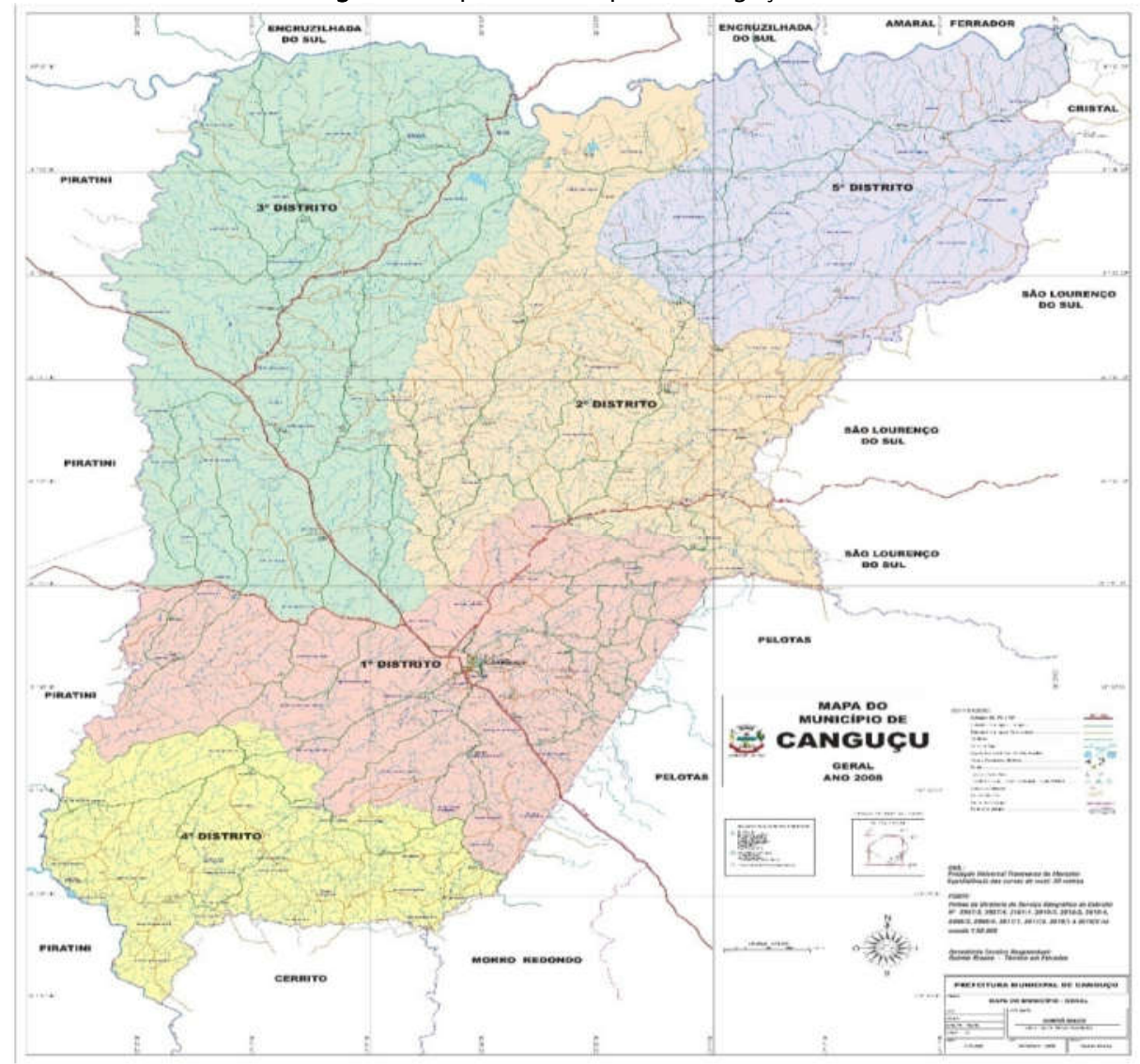

Fonte: IBGE (2010)

Neste território a agricultura familiar configura-se pela produção diversificada de produtos para autoconsumo, realizada por membros da família. Ao tratar sobre o produtor que desenvolve a agricultura familiar, Whitaker $(2009$, p. 37) salienta que:

Estamos falando de um rural comprometido com a terra enquanto mãe natureza, aquela que nos mata a fome com seus generosos frutos. Não estamos falando de ações que esgotam a terra e extraem dela mais do que poderia ou deveria produzir.

Os produtos para o autoconsumo são produzidos para a família em hortas, pomares e em pequenas criações de animais. A culinária pomerana é transgeracional e, geralmente, fica a cargo das mulheres, sendo que as matriarcas ensinam receitas para as meninas mais jovens. Muitos saberes são relacionados à preservação dos alimentos como: conservas, defumação, secagem de plantas, como, por exemplo, chás que são utilizados como remédios naturais. Quanto aos meninos, comumente eles aprendem 
com os patriarcas o trabalho relacionado ao manejo da terra, maquinários e a lida com animais. As crianças pomeranas auxiliam desde pequenas nas práticas que a família exercita. São rituais em que elementos da memória, dos saberes e da tradição são transmitidos das gerações mais antigas para as mais novas, contribuindo para a manutenção dos ritos e do modo de vida.

As famílias pomeranas praticam a religião Luterana e as crianças convivem desde o nascimento com este universo religioso. Realizam cerimônias como o batismo, confirmação de fé e casamento. Também expressam a sua religiosidade no cotidiano, por meio de orações e devoções bíblicas. No trabalho, a religiosidade envolve diferentes rituais, tais como orações para que o clima seja favorável. Um exemplo é a festa da colheita, realizada na igreja, momento em que os camponeses trazem parte da sua produção para o altar, como forma de agradecer pela bênção concedida.

De acordo com Bahia (2011), os pomeranos não vivenciam uma visão única da religião Luterana, mas realizam uma idiossincrasia, em geral vinculada ao modo de vida camponês, incluindo crenças e rituais de natureza mística que entrariam em conflito com a religião pomerana oficial. Conforme Woortmann e Woortmann (1997, p. 15):

O saber mágico e as crenças religiosas, para os trobriandeses, tanto quanto para os sitiantes (benzer o pasto e o gado ou recorrer aos santos, por exemplo), são tão necessários quanto o saber 'técnico', e conhecê-los é fundamental para que o antropólogo possa dar sentido ao esforço produtivo.

Em relação à língua, cabe destacar que as crianças de comunidades pomeranas, que vivem basicamente no campo, experienciam o universo camponês junto aos seus pais e/ou com um pequeno ciclo familiar e, não raras vezes, falam somente o pomerano. Sendo assim, a ida para a escola significa um momento de grande mudança em suas vidas, seja pela alteração em sua rotina diária ou pela comunicação que se dará prioritariamente em Língua Portuguesa. A Campanha de Nacionalização, ocorrida no ano de 1938, foi um dos momentos mais marcantes no que se refere à proibição linguística. As línguas denominadas "estrangeiras" foram proibidas em locais públicos, como consta no Art. 15. do Decreto-lei Federal no 1.545, de 25 de agosto de 19397: "É proibido o uso de línguas estrangeiras nas repartições públicas, no recinto das casernas e durante o serviço militar".

Essa publicação foi elaborada especificamente para a adaptação de imigrantes e seus descendentes em território brasileiro. Diante dessas ações regulatórias, os pomeranos e demais imigrantes sofreram drásticas consequências através deste silenciamento forçado. De acordo com Tressmann (2005), essas ações nacionalistas foram organizadas com consciência sobre os efeitos devastadores que "a quebra da unidade linguística" (TRESSMANN, 2005, p. 100) acarretaria aos povos imigrantes e seus descendentes. A língua proibida acelerou o processo de aculturação dos imigrantes teuto-brasileiros pois "[...] a substituição do Português como língua de uso cotidiano, especialmente no seio da família, é indício de que a transformação atingiu a um grau de irreversibilidade em todas ou quase todas as esferas da cultura" (TRESSMANN, 2005, p. 100).

Inter-Ação, Goiânia, v.46, n.2, p. 556-576, maio/ago. 2021. Disponível em: <http://dx.doi.org/10.5216/ia.v46i2.67811>. 
BERWALDT, M. G. M.; NOGUEIRA, G. M

Embora em Canguçu-RS, Brasil, a Língua Pomerana seja cooficial ${ }^{8}$, o que se observa, em especial nos espaços educativos, é a exclusividade da comunicação em português. A Língua Pomerana foi por muito tempo considerada apenas um dialeto, diante da inexistência de uma escrita oficial do idioma. De acordo com Ismael Tressmann (2005), a Língua Pomerana só passou a ter grafia no Brasil em 2000, quando houve a intensificação de pesquisas sobre essa temática no estado do Espírito Santo. A escrita pomerana passou a ter um status oficial em 2006, quando foi editado o Dicionário Pomerano-Português, que contribuiu para os processos de reconhecimento de língua cooficial em diferentes municípios ${ }^{9}$ e a criação de programas e políticas de fortalecimento da Língua e da cultura, como foi o caso do PROEPO ${ }^{10}$, instituído em 2005.

\section{CONTEXTO DA COMUNIDADE E DA ESCOLA}

O processo de entrada das crianças provenientes do campo na escola, em geral ocorre de modo diferenciado do contexto urbano. Enquanto nos grandes centros o ingresso à escola, em muitos casos, se dá após a licença maternidade, na zona rural esse tempo é mais alongado, pois as famílias tendem a manter seus filhos por mais tempo sob seus cuidados. Nas comunidades camponesas localizadas no território pomerano da Serra dos Tapes, grande parte das crianças vai para a escola apenas no tempo estabelecido pela legislação, ou seja, aos quatro anos de idade ${ }^{11}$. Nesse momento, observamos que as crianças que são monolíngues em pomerano têm mais dificuldade na adaptação escolar, pois, além da rotina na escola ser diferente da que estão acostumados, não entendem a Língua Portuguesa.

$\mathrm{Na}$ escola em que a pesquisa foi realizada, o horário da aula é das $13 \mathrm{~h} 30$ às 17h15. A maioria das crianças utiliza o ônibus municipal como transporte, sendo que o trajeto de casa até a escola pode durar até uma hora para aquelas que moram mais afastadas $^{12}$. Cabe colocar que apesar da legislação para a Educação Infantil do campo indicar que as ofertas das escolas sejam sempre nas próprias comunidades para evitar a nucleação e deslocamentos das crianças, nessa localidade ainda não é efetivo esse processo. Porém, existe uma organização que respeita a nucleação com menor percurso para as crianças entre residência e escola ${ }^{13}$.

Em relação ao primeiro momento da inserção no campo empírico da pesquisa, ocorreu no pátio da escola no dia 25 de fevereiro, primeiro dia letivo do ano de 2019. As crianças estavam em filas, separadas por adiantamento, enquanto aguardavam o toque da sineta que marcava o início das atividades. As menores, que iriam para a pré-escola, estavam acompanhadas pela mãe, ou por um irmão, que esperaram neste primeiro dia de aula até o final do turno. Para a maioria dessas crianças, este momento é o primeiro contato com um espaço institucional e, na fase de adaptação à escola, em especial na Educação Infantil, o choro é algo bastante comum.

Cabe ressaltar que na turma do nível II, em que a pesquisa foi realizada, a metade das crianças era falante apenas do pomerano. A professora, que é natural da comunidade, é bilíngue em pomerano e português, o que facilitava a comunicação com as crianças que só falavam o pomerano.

Destacamos nesta primeira inserção no campo de pesquisa, nos cinco dias consecutivos de observação, que as crianças basicamente não falavam, não conversavam entre si, apenas respondiam às perguntas da professora com uma voz 
quase inaudível, apesar de a grande maioria conhecê-la por ser moradora na comunidade.

No mês de abril ocorreu a segunda inserção no campo empírico da pesquisa que foi de três dias. Neste período, percebemos que as crianças já apresentavam avanços em relação à comunicação entre os pares e escolhiam se sentar perto dos colegas por afinidade. O mesmo foi observado em junho, momento da terceira observação realizada em dois dias consecutivos, ou seja, em sala de aula as crianças interagiam mais, trocavam algumas palavras em Língua Portuguesa e chamavam umas às outras. Com a professora, a interação também se dava sempre em Língua Portuguesa, mesmo com certa dificuldade por parte das crianças e com constantes correções da professora.

O toque da sineta anunciava o recreio, que era o momento mais esperado pelas crianças. Era visível a expressão de expectativa, um pouco de agito e ansiedade quando estava perto da hora de irem para o pátio, pois era o único momento de brincar livremente, pois os outros poucos momentos de brincadeira eram conduzidos pela professora (DIÁRIO DE CAMPO, 2019).

O Parecer n० 20 de 2009, que trata da Diretrizes Curriculares Nacionais para a Educação Infantil, destaca que a brincadeira é fundamental para a criança pequena, especialmente porque:

Brincar dá à criança a oportunidade para imitar o conhecido e para construir o novo, conforme ela reconstrói o cenário necessário para que sua fantasia se aproxime ou se distancie da realidade vivida, assumindo personagens e transformando objetos pelo uso que deles faz (BRASIL, 2009, p. 07).

As crianças formavam fila com a professora para atravessar a rua, pois o pátio ficava no terreno do prédio principal, do outro lado da estrada. No recreio, elas também interagiam com as crianças maiores, que comumente são irmãos, primos ou amigos. Em relação ao fato de as crianças interagirem com outras além da sua turma, Corsaro (2011) considera que elas tendem a ampliar seus contatos sociais, devido às experiências vividas.

Conforme o referido autor, "[...] ao invés de limitar seus contatos sociais a um ou dois colegas, as crianças frequentemente desenvolvem relações estáveis com vários deles, como forma de maximizar a probabilidade de ingresso bem-sucedido e a interação satisfatória com as demais" (CORSARO, 2011, p. 164).

A comunicação entre elas nos momentos de brincadeira no pátio da escola acontecia, na maioria das vezes, em Língua Pomerana. Ao que tudo indica, os espaços de uso das línguas estavam bem estabelecidos, ou seja, nos momentos formais em sala de aula a Língua Portuguesa predominava e, no pátio da escola, entre as crianças, o pomerano era a língua utilizada ${ }^{14}$.

Uma das brincadeiras que observamos, chamada pelas crianças de "cavalo cego" era realizada da seguinte maneira: as crianças maiores pegavam uma madeira oca, fincavam uns tocos e sentavam-se um de cada lado do toco e giravam na maior 
velocidade que conseguiam. No entorno ficavam as crianças menores, observando e torcendo pelos que estavam girando.

Consideramos, contudo, que brincadeira é também uma prática social, que se constrói no encontro com o outro, em que "[...] o processo coletivo de brincar envolve a coordenação de ideias, papéis significados e ações, exigindo constantes negociações e ajustes pelas crianças, sendo, portanto, passível de rupturas" (BORBA, 2005, p. 123).

Outras brincadeiras que observamos na hora do recreio foram: escondeesconde, pega-pega e amarelinha, geralmente realizadas no cemitério localizado no pátio da escola ${ }^{15}$. Corsaro (2009) percebeu que as crianças produzem e compartilham um conjunto de atividades, rotinas, artefatos, valores e interesses entre si e denominou essas ações 'cultura de pares'. Ao observar a fala das crianças, percebemos que o cemitério suscitava imaginação e fantasia, pois elas traziam diferentes narrativas sobre lendas daquele lugar. Algumas eram recontadas nos momentos em família e outras criadas pelas próprias crianças como, por exemplo, o caso de uma mulher vestida de noiva que saía do túmulo à noite (DIÁRIO DE CAMPO, 2019). Cabe colocar que a prática de narrar contos é algo bastante característico das famílias pomeranas, aspecto também identificado por Bahia (2010) em sua pesquisa. Percebemos que as crianças acreditavam que os contos tratavam de histórias verdadeiras, indicando inclusive certo temor em seu próprio relato, evidenciando gritos e expressões de medo. Uma das histórias que as crianças contavam recorrentemente na hora do recreio, era a de um menino que tinha ido se banhar escondido dos pais na sanga e se afogou. Elas relatavam que o menino ficava sentado perto do lugar para espantar as crianças que teimavam em ir lá. Comumente as lendas retratam casos de acidentes ocorridos na localidade e são contadas no intuito de que as crianças sintam medo e não desobedeçam (DIÁRIO DE CAMPO, 2019).

De acordo com Sarmento (2003), é o imaginário infantil que potencializa a compreensão e significação do mundo pelas crianças. Elas desenvolvem a sua imaginação a partir do que observam, experimentam, ouvem e interpretam das experiências vividas, da mesma forma que "[...] as situações que imaginam lhes permitem compreender o que observam, interpretando novas situações e experiências de modo fantasista, até incorporarem como experiência vivida e interpretada" (SARMENTO, 2003, p. 64).

Outro espaço no qual as crianças brincavam no momento do recreio era o armazém de fumo, também localizado no pátio da escola. Elas confeccionavam bonecos com a palha de milho, apenas amarrando a palha para dar formato de uma cabeça arredondada e, muitas vezes, mostravam como as mães fazem o artesanato em palha de milho. Além disso, as crianças corriam atrás das galinhas, que circulam livremente no pátio, e colhiam bergamotas nas árvores localizadas nos arredores.

As crianças conversavam sobre quais estratégias utilizar para conseguir colher as bergamotas mais maduras no alto da árvore, porque sabiam por suas vivências no contexto familiar, que era ali que ficavam as frutas mais saborosas. Quando os pássaros haviam comido parte da fruta, as crianças separavam a parte bicada das que elas podiam comer, e diziam "a fruta mais doce é aquela que o passarinho bicou, eles sabem escolher" (DIÁRIO DE CAMPO, 2019, p. 29).

Ao longo das observações, percebemos que as crianças inventavam e reinventavam a forma de brincar e interagir no momento do recreio com objetos 
próprios do lugar, em geral advindos da natureza. Um exemplo de outra brincadeira que observamos é Wurst Dreige (pronunciado Vust Dréia), que significa máquina de fazer linguiça em pomerano. Essa brincadeira é muito semelhante ao conhecido Cabo de Guerra, o que a diferencia é que as crianças vão falando wurst dreige, enquanto de mãos dadas se entrelaçam uma a uma, formando uma corrente, então aquela criança que fica de fora começa a puxar as outras. As brincadeiras de imitação refletem a cultura desta comunidade, como é o caso de o brincar de feira ${ }^{16}$, conforme é possível perceber no excerto a seguir retirado do Diário de Campo (2019, p. 23):

As crianças fazem uma busca no pátio da escola e trazem todos os elementos que encontram, pinhas, sementes, bergamota. Então organizam ao pé de uma árvore o comércio, simulando o que acontece em uma feira livre, em que uns vendem, outros compram produtos. Na continuidade da brincadeira eles vão invertendo os papéis.

Consideramos que as negociações entre as crianças são necessárias para que os significados sejam compreendidos e compartilhados, os interesses individuais e coletivos sejam articulados a fim de que todos os envolvidos desejem continuar na brincadeira. De acordo com Borba (2005, p. 129):

\footnotetext{
Brincar com outra criança não é uma atividade simples, que ocorre naturalmente bastando duas ou mais crianças se juntarem, por mais que assim o pareça aos nossos olhos de adultos. Ao contrário, envolve um complexo processo de construção e de negociação de significados, que só é possível quando existe uma base comum de conhecimento sobre a qual as crianças possam agir de forma colaborativa. Os scripts podem contribuir para a constituição dessa base comum e formar um tipo de conhecimento partilhado a partir do qual as crianças organizam e sustentam uma situação interativa de brincadeira.
}

Assim, a brincadeira não é algo inato no ser humano, pois mesmo que exista uma motivação interna para os aspectos lúdicos, o brincar exige aprendizagem de procedimentos que tornam a brincadeira e/ou o jogo possível.

Além das brincadeiras citadas, também observamos que as crianças procuravam borboletas nos casulos vazios, tentavam identificar qual pássaro era do ovo no ninho, escolhiam a melhor árvore para a brincadeira de casinha, ou o melhor esconderijo. Nos momentos vivenciados no pátio da escola, as que falavam apenas o pomerano também interagiam com crianças que falavam somente a Língua Portuguesa. A barreira linguística não era impedimento e a linguagem corporal, por meio de gestos, era a utilizada na comunicação. Em uma das observações registramos o seguinte:

Um menino estava sentado sozinho e então uma colega falou com
ele. Ele ficou olhando para ela demonstrando não compreender o
que ela tinha dito, então a menina estendeu a mão para ele, como 
BERWALDT, M. G. M.; NOGUEIRA, G. M

quem convida para algo e logo saíram correndo" (DIÁRIO DE CAMPO, 2019, p. 26).

Como é possível perceber neste relato retirado do Diário de Campo, a comunicação para brincadeiras e diversão ia além da oralidade e, nesta perspectiva, os laços eram fortalecidos entre risadas e aventuras.

De acordo com Brougère (1998, p. 4), "o conjunto das regras de jogo disponíveis para os participantes numa determinada sociedade compõe a cultura lúdica dessa sociedade e as regras que um indivíduo conhece compõem sua própria cultura lúdica". Independentemente do jogo ser 'tradicional' ou 'atual', as regras são particularizadas por cada grupo que as constrói, ou seja, elas variam em cada situação de acordo com as características dos indivíduos e dos grupos. Isso demonstra que a cultura lúdica é, segundo Brougère (1998, p. 4), "um conjunto vivo" em que as condições sociais, culturais, temporais e espaciais interferem no modo como ela é vivida. Além disso, o referido autor salienta o conceito de cultura lúdica, definindo-o da seguinte forma:

A cultura lúdica é, então, composta de um certo número de esquemas que permitem iniciar a brincadeira, já que se trata de produzir uma realidade diferente daquela da vida quotidiana: os verbos no imperfeito, as quadrinhas, os gestos estereotipados no início das brincadeiras compõem assim aquele vocabulário cuja aquisição é indispensável ao jogo (BROUGÈRE, 1998, p. 4).

Considerando o excerto acima, é possível reconhecer que a cultura lúdica não é estática e imutável nos diversos contextos, ao contrário, ela está fortemente imbricada na cultura local, nos modos de ser e de viver das pessoas num determinado espaço e tempo. Isso ficou evidente nesta seção ao descrevermos as diferentes formas pelas quais as crianças viveram a cultura lúdica no espaço escolar durante o ano de 2019.

\section{A LÍNGUA COMO INSTRUMENTO DE INTERAÇÃO E MANIFESTAÇÃO DA CULTURA}

Conforme disposto na seção anterior, a Língua Portuguesa é falada na maior parte do tempo na escola. Contudo, na observação realizada no primeiro dia de aula, a professora começou se apresentando, em português e em pomerano, e anotou algumas singularidades das crianças no que se refere à comunicação. A professora relatou que escreve no caderno as características das crianças para auxiliar o conhecimento sobre cada uma delas. Após esse momento, ela deu início às tarefas diárias com a música "Olá amiguinho como vai", contudo, era perceptível que poucas crianças acompanhavam a professora na canção entoada em Língua Portuguesa. Na continuidade da aula, foram entregues folhas fotocopiadas com imagens, em geral retiradas de sites da internet, para as crianças colorirem (DIÁRIO DE CAMPO, 2019).

No intuito de minimizar a incompreensão das crianças em relação ao que deveria ser realizado, a professora passava de mesa em mesa e explicava para cada criança, sendo que as instruções eram dadas nas duas línguas quase que simultaneamente e, não raras vezes, com o recurso de gestos.

Um caso que gostaríamos de salientar, percebido no primeiro dia da quarta observação, realizada em setembro, é o de uma menina que no início do ano era 
monolíngue em pomerano e ao longo dos meses passou a falar somente em Língua Portuguesa. A conversa de uma das pesquisadoras com a criança, registrada no Diário de Campo é bastante elucidativa:

\begin{abstract}
Pesquisadora: Mas o que houve? Por que não falar mais a língua dos teus pais?

Sofia (falando português com muita dificuldade): Não gosto de falar na escola, as crianças dão risada, acham engraçado. Ontem fui no médico com minha mãe, e ele disse para que minha mãe não me deixasse falar pomerano, que precisava falar português. Daí eu não vou mais falar. Ninguém mais vai rir de mim (Diário de campo, 2019, p. 23).
\end{abstract}

Relatos em relação a essa situação de "vergonha de falar em pomerano" fazem parte do cotidiano desse povo, sendo um fato recorrente em algumas narrativas observadas. Isso ocorre também com outros grupos culturais que falam a língua materna basicamente no ambiente familiar.

Como exemplo citamos a pesquisa de Aguiar (2018) sobre a coexistência da Língua Portuguesa e Crioula cabo-verdiana em uma cidade no continente africano. Os resultados da pesquisa indicaram que:

O uso da Língua Portuguesa é dominante nas salas de aula observadas, por ser compreendido pelas professoras como o "lugar do ensino", um lugar formal. À Língua Crioula cabo-verdiana ficou reservado os momentos informais, como no recreio e horários de entrada e saída da referida escola (AGUIAR, 2018, p. 127).

Cabe destacar que os pomeranos foram considerados por muito tempo como uma cultura inferior à germânica e, de um certo modo, foram se conformando com este estigma. No jogo das relações macropolíticas das culturas dominantes, a Língua Pomerana foi por muito tempo considerada apenas um dialeto, já que, oficialmente, a escrita pomerana existe a partir de 2006, quando surgiu o Dicionário PomeranoPortuguês. Os processos de reconhecimento de língua cooficial em diferentes municípios tiveram impulso com a criação de programas e políticas de fortalecimento da língua e da cultura. Em relação à utilização da língua no contexto escolar, Aguiar e Nogueira (2019, p. 155) destacam que:

Refletir sobre a situação educacional acerca das línguas significa compreender que a oficialização de uma língua exige além do desejo da população, movimentos de pressão, tensões e embates, muito estudo e pesquisa que sustentem e justifiquem cientificamente a possibilidade de sua oficialização.

O caso das crianças que não querem mais falar a sua língua de origem é uma situação que se repete cotidianamente. Pais desistem de ensinar a língua materna aos filhos e netos pela irrelevância e desprestígio que a mesma representa no cenário de 
BERWALDT, M. G. M.; NOGUEIRA, G. M

valorização social. Desta forma, a Língua Pomerana vem sendo silenciada e, atualmente o número de famílias que preserva a tradição oral em casa foi drasticamente reduzido. De acordo com Tressmann (2005, p. 97-98):

Há pais, ainda, que falam muito pouco o Pomerano com seus filhos. Eles justificam o fato de preferirem que os filhos falem mais a língua oficial devido aos sentimentos de humilhação e vergonha que vivenciaram em situações formais na cidade; temem que a mesma situação ocorra com os filhos. Encontramos uma outra motivação, não desvinculada da primeira. É o caso de muitas crianças que após terem frequentado a escola por alguns meses, passam a falar cada vez mais o Português em casa e menos o Pomerano. Estes comportamentos refletem nitidamente a posição oficial da escola em relação ao status das línguas. Muitas professoras, de origem pomerana e brasileira, consideram o Pomerano "apenas um dialeto" que, por ser uma língua predominantemente ágrafa e sem gramática normativa, não teria "status oficial de língua verdadeira". Além de gozar do prestígio de língua verdadeira, o Português é um idioma que carrega conotações positivas como cultura, civilização e modernidade.

É comum ainda na atualidade, até mesmo em discursos formais, a denominação da Língua Pomerana como um dialeto. Essa definição é carregada de preconceito, e seu tom, muitas vezes depreciativo, é classificado pelo próprio povo pomerano como no excerto acima. "Afora esses atributos, consideram o Pomerano 'língua de gente da roça', culturalmente atrasada e socialmente inferior, enquanto que o Português é a língua oficial do país", Tressmann (2005, p. 98).

Ao que tudo indica, na turma de pré-escola observada, a professora procurava respeitar as individualidades das crianças, contudo era preciso avançar nos objetivos demandados pela escola e avançar na aprendizagem da Língua Portuguesa para as crianças compreenderem as orientações dadas. Como exemplo disso, podemos citar o material preparado pela professora, produzido somente em Língua Portuguesa. Nas paredes da sala de aula, especialmente nos cartazes que apresentam as letras com figuras correspondentes, tal como os cartazes de consciência fonológica com a movimentação dos lábios referentes a determinadas letras são também no idioma português.

Diante disso, problematizamos as práticas observadas nesta turma, questionando sobre a forma que foram pensadas e quem participa do seu planejamento. Fica evidente que nas escolhas o que pode e o que não pode ser proposto, "[...] esta relação entre cultura e poder: quanto mais importante - mais central - se torna a cultura, tanto mais significativas são as forças que a governam, moldam e regulam", afirma Hall (1997, p. 40). E neste movimento, fica evidente que as padronizações vão se efetivando e se instituindo práticas homogeneizadoras, aspecto discutido também por Norões (2018) ao problematizar marcos históricos que indicam a negligência das autoridades políticas com a educação de imigrantes.

Contudo, apesar de a Língua Portuguesa ir se tornando a hegemônica no cotidiano da sala de aula, foi possível observar no mês de novembro, a última semana de inserção no campo empírico da pesquisa, a finalização dos projetos da turma: "Quem 
somos? Somos Pomeranos!" e "O que significa ser pomerano nesta localidade?". A fala das crianças, que foi registrada em Diário de Campo, mostra mesmo que de forma bastante sintética um pouco sobre como eles vivenciam e internalizam a sua cultura no contexto familiar:

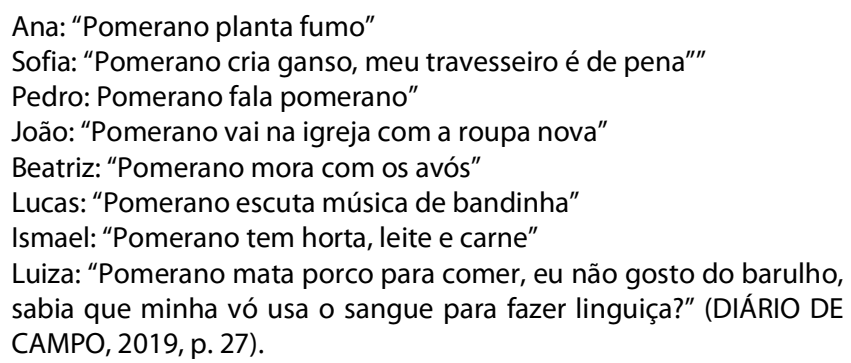

Interessante observar como, mesmo que de forma tímida, os aspectos da cultura vão aparecendo nas colocações das crianças em relação ao ser pomerano. Elas identificam atividades cotidianas como plantação de fumo, cultivo da horta, produção de leite e carne como característica deste povo. Assim como fazem referências ao tipo de música característico e ao hábito de reservar a roupa mais nova para ir à igreja. A Língua Pomerana também é atribuída como algo particular dessas pessoas, bem como morar com a família estendida, como os avós. Chama atenção as colocações de Sofia ao dizer que tem travesseiro feito com pena de ganso e de Luiza ao comentar que não gosta do barulho que o porco faz no momento do abate e que a sua avó usa o sangue para fazer linguiça. A fala dessas duas crianças, diferente das demais, indica aspectos pessoais, o que as inclui como pomeranas.

Outra atividade observada foi uma saída de campo em que uma das pesquisadoras participou do roteiro programado pela professora junto às famílias. Com um ônibus escolar cedido pelo município, foram na casa de cada uma das crianças e as famílias mostravam algo da sua cultura e rotina. Cabe destacar que nas famílias que eram monolíngues em pomerano, a professora mediava o diálogo. Todas as crianças da turma que vivenciam o contexto camponês, com as características próprias da vida no campo, participaram da atividade, mesmo as que não são de origem pomerana. Este foi o único momento ao longo do ano, dos dias que observamos, que a crianças pomeranas eram o centro da proposta.

Observamos que receita culinária, plantação, animais, vestes, foram os artefatos apresentados pelas famílias em um momento singular de diversão e interação entre os membros da comunidade local. A família do Lucas apresentou a foto das viúvas de preto, costume relacionado às vestimentas pomeranas para expressar o luto entre as mulheres. As noivas também utilizam preto, e para este costume existe diferentes versões. A mãe do Lucas, por exemplo, relatou que reutilizar os vestidos após o casamento era uma forma de economizar, mas também podia significar luto em relação aos "casamentos arranjados". E ainda pelo direito da noite de núpcias com a noiva, em 
um casal de servos imigrantes, ser concedido ao senhor, dono da propriedade (DIÁRIO DE CAMPO, 2019, p. 23).

Sofia, uma das crianças participantes da pesquisa e a que disse usar travesseiro de ganso, continuou seu propósito de não falar mais a Língua Pomerana e seu português aos poucos foi sendo aperfeiçoado, com um sotaque característico dos camponeses pomeranos. As outras crianças, monolíngues em pomerano, também foram ampliado o seu repertório do português e sua fala se misturava nas duas línguas. Portanto, foi perceptível que todas as crianças tinham intenção de aprender a Língua Portuguesa, uma vez que escutam recorrentemente que para ter um futuro diferente, melhor que dos pais, precisam falar português e estudar na universidade.

\section{CONSIDERAÇÕES FINAIS}

Neste artigo apresentamos dados de uma pesquisa etnográfica sobre o cotidiano de 13 crianças de uma comunidade pomerana, realizada em uma turma de nível II da Educação Infantil de uma escola municipal de Ensino Fundamental do campo, situada na Serra dos Tapes no Rio Grande do Sul, Brasil. Tivemos por objetivo conhecer como as crianças vivenciaram a cultura lúdica e enfrentaram os desafios do cotidiano no espaço escolar. Observamos como aconteceu a apropriação da Língua Portuguesa e das rotinas na escola ao longo de 2019.

Nesta investigação, em que as crianças foram os principais sujeitos estudados, observamos que a língua foi um fator importante neste processo de inserção na escola. Isso porque dois terços das crianças da turma da Educação Infantil falavam apenas a Língua Pomerana e um terço delas era bilíngue nas Línguas Portuguesa e Pomerana. $O$ fato de a professora ser de descendência pomerana, ser fluente nas línguas pomerana e portuguesa e viver na comunidade foi muito importante para o processo de adaptação das crianças, considerando que elas passaram a conviver com uma outra realidade diferente da que conheciam até então. Entendemos que mesmo que a professora não tivesse consciência do seu papel social em relação à salvaguarda da língua e da cultura pomerana, na sua prática de tradução quase que simultânea da aula da língua portuguesa para a pomerana, tornou o processo de transição mais ameno para as crianças monolíngues em pomerano.

Observamos que inicialmente as crianças apresentavam dificuldades de comunicação, mas que no decorrer do ano houve a transição da Língua Pomerana para Língua Portuguesa. Isso, de certa forma, teve como consequência um certo silenciamento da Língua Pomerana.

Observamos também que aos poucos as crianças pomeranas, ao vivenciarem suas infâncias junto aos seus pares, foram se apropriando do novo contexto e se transformando. Como estratégia de adequação aos novos desafios ocasionados pela ruptura entre a cultura do lar e a da escola, a infância se delineia entre ajustes de ideais de comunicação e interação para adaptar-se ao novo grupo. As brincadeiras no pátio, nos momentos livres, mostraram-se fundamentais no processo de interação e reprodução cultural, pois além das brincadeiras que imitavam os cotidianos da cultura, as crianças compartilhavam modos de brincar dos seus antepassados que, diante da ausência de brinquedos industrializados, necessitavam reinventar os momentos de diversão por meio dos materiais não estruturados, que compunham o cenário do lar. A 
cultura manifestava-se no brincar, principalmente naqueles períodos que as crianças corriam livres pelo pátio sem o comando dos adultos. O "recreio" foi o momento registrado como maior potencializador da socialização e promoção da cultura entre as crianças.

Por fim, cabe colocar que consideramos que esta pesquisa contribui para ampliar os estudos da infância e da Educação Infantil, uma vez que trata-se de um grupo de crianças pomeranas inseridas em uma escola municipal de Ensino Fundamental do campo. A problematização sobre grupos minoritários, no que tange à preservação da cultura, neste caso, da Língua Pomerana como uma língua materna silenciada, também se fez presente ao longo da pesquisa, especialmente nas instituições educativas. Este estudo colabora com as reflexões sobre a necessidade de investir em instituições de Educação Infantil para atender às necessidades específicas das crianças nesta etapa da educação básica no campo.

Além disso, acreditamos que esta pesquisa evidencia o desafio das instituições que atendem crianças imigrantes, principalmente de grupos minoritários, em rever seus projetos pedagógicos a fim de contemplar e valorizar as suas especificidades no cotidiano escolar, em especial no que ser refere às línguas e manifestações culturais.

\section{THE DAILY LIFE OF POMERANIAN CHILDREN IN EARLY CHILDHOOD EDUCATION}

ABSTRACT: This article presents data from a research that aimed to know, how a group of Pomeranian children experienced the playful culture and faced the challenges in their daily lives, in a level II class of Early Childhood Education, from an elementary school, throughout 2019. The investigation was carried out through the analysis of documents and ethnography, with the sociology of childhood as a theoretical reference. Among the results found, we observed that language was an impacting factor in the insertion process at school, since two thirds of the children spoke only the Pomeranian language and one third was bilingual in Portuguese and Pomeranian. Throughout the year, the Portuguese language was predominant and resulted in the silencing of the Pomeranian language, demonstrating a relationship of subordination from one culture to another.

KEYWORDS: Children. Childhood. Pomeranian Community. Child Education.

\section{LA VIDA COTIDIANA DE LOS NIÑOS POMERANIOS EN LA EDUCACIÓN INFANTIL}

RESUMEN: Este artículo presenta datos de una investigación que tuvo como objetivo conocer, cómo un grupo de niños pomeranios vivieron la cultura lúdica y enfrentaron los desafíos en su 
BERWALDT, M. G. M.; NOGUEIRA, G. M

vida diaria, en una clase de nivel II de educación infantil, desde una escuela primaria, a lo largo de 2019. La investigación se realizó mediante el análisis de documentos y etnografía, con la sociología de la infancia como referente teórico. Entre los resultados encontrados, observamos que el idioma fue un factor de impacto en el proceso de inserción en la escuela, ya que dos tercios de los niños hablaban solo la lengua pomerania y un tercio era bilingüe en portugués y pomerania. Durante el año, la lengua portuguesa fue predominante y resultó en el silenciamiento de la lengua pomerania, demostrando una relación de subordinación de una cultura a otra.

PALABRAS CLAVE: Niños. Infancia. Comunidad de Pomerania. Educación Infantil.

\section{NOTAS}

1 - Emigrantes provenientes da extinta Pomerânia, região que atualmente se encontra em área de fronteira, entre países da Alemanha e da Polônia. Os pomeranos exercem seu modo o modo de vida camponês na comunidade da pesquisa e um dos importantes patrimônios culturais da cultura é a Língua Pomerana, ensinada de forma transgeracional e utilizada principalmente no lar. 2 - O município de Canguçu compreende uma área de 3.525,3 km e, em 2019, contava com 53.259 habitantes.

3 - Optamos por utilizar a expressão espaço escolar, porque mesmo se tratando de uma turma de nível II da Educação Infantil, o que de fato as crianças vivenciaram foi uma rotina muito próxima do Ensino Fundamental, o que será observado e problematizado ao longo do texto.

4 - Conferência realizada em Potsdam na Alemanha, entre 17 de julho e 02 de agosto de 1945, tendo como objetivos o estabelecimento da ordem pós-guerra, os tratados de paz e o contorno dos efeitos da guerra.

5 - Os pomeranos também se estabeleceram em outros estados brasileiros, como Paraná, Espírito Santo, Rondônia e Santa Catarina.

6 - Decreto nº 6.040, de 7 de fevereiro de 2007. Assinado pelo então Presidente da República Luiz Inácio Lula da Silva.

7 - Disponível em: https://www2.camara.leg.br/legin/fed/declei/1930-1939/decreto-lei-1545-25agosto-1939-411654-publicacaooriginal-1-pe.html. Acesso em: nov. 2020.

8 - Lei Estadual N. 3473/2010 que trata da cooficialização da Língua Pomerana em Canguçu.

9 - Com amparo na Constituição de 1988 (artigos 210, 215 e 216), nas Convenções Internacionais, nas premissas da Declaração Universal dos Direitos Linguísticos (Barcelona, 1996) e nos decretos (3.551/2000 regulamentam o processo de Registro de Bens Culturais de Natureza Imaterial). Memória e educação e territorialidade se implicam mutuamente nos processos de luta por direitos linguísticos de língua materna.

10 - O Programa de Educação Escolar Pomerana (Proepo) é um programa político e pedagógico que visa valorizar e fortalecer a cultura e a língua oral e escrita pomerana que está em vigor.

11 - Emenda Constitucional n 05/2005 torna a educação básica obrigatória e gratuita dos 4 (quatro) aos 17 (dezessete) anos de idade, assegurada inclusive sua oferta gratuita para todos os que a ela não tiveram acesso na idade própria. Disponível em: http://www.planalto.gov.br/ccivil_03/constituicao/Emendas/Emc/emc59.htm. Acesso em: nov. 2020.

12 - Conforme consta no Projeto Político Pedagógico (Canguçu, 2020), "cinco linhas de estrada sem asfalto, que recolhem alunos de 12 localidades: Harmonia, Taquaral, Benedito, Picada das Antas, Picada Moinhos, Bom Jesus, Santana, Caipira, Fortaleza, Sesmaria, Cerrito, Potreiros". 
13 - Resolução $\mathrm{n}^{\circ} 2$, de 28 de abril de 2008. Disponível em: http://portal.mec.gov.br/index.php?option=com_docman\&view=download\&alias=13800rceb001-02-pdf\&category_slug=agosto-2013-pdf\&ltemid=30192. Acesso em: nov. 2020.

14 - Situação semelhante foi relatada na dissertação intitulada "Línguas crioula cabo-verdiana e portuguesa: a coexistência das línguas materna e oficial em turmas de $1^{\circ}$ e $2^{\circ}$ anos de uma escola de ensino básico em Cabo Verde, de Kelly de Aguiar Arruda, defendida em 2018, no Programa de Pós-graduação em Educação. Acesso pelo link: http://argo.furg.br/?RG001411974.

15 - No mesmo terreno da escola estão a igreja e o cemitério, o que é comum em comunidades de imigrantes pomeranos.

16 - Algumas famílias das crianças nesta comunidade, comercializam seus produtos em feiras na cidade (região urbana) carregam os insumos em caminhões, que servem como estrutura para os caixotes de madeira com frutas, legumes e verduras. Em certos dias as crianças acompanham os familiares na jornada.

\section{REFERÊNCIAS}

ARRIADA, E. Pelotas - Gênese e Desenvolvimento Urbano (1780 - 1835). Pelotas: Armazém, 1994.

ARRUDA, K. A.; NOGUEIRA, G. M. Tensões e disputas entre a Língua Crioula caboverdiana e a Língua Portuguesa desde a independência de Cabo Verde. RELVA, Juara/MT/Brasil, v. 6, n. 2, p. 139-159, jul/dez. 2019.

BAHIA, J. O Tiro da Bruxa: Identidade, Magia e Religião na Imigração Alemã. Rio de Janeiro: Garamond, 2011.

BEIERSDORF, C. R.; WEIDUSCHADT, P. Arroio do Padre / RS e sua identidade luterana: Práticas de educação e cultura de uma comunidade (1950-1960). Revista LatinoAmericana de História, UNISINOS. v. 2, n. 7, p. 1-17, 2013.

BORBA, Â. M. Culturas da infância nos espaços - tempos do brincar. Niterói: UFF, 2005. Tese (Doutorado em Educação), Programa de pós-graduação em Educação, Universidade Federal Fluminense, 2005.

BRASIL. Conselho Nacional de Educação. Resolução CNE/CEB n 20/2009. Diretrizes Curriculares Nacionais para a Educação Infantil. Brasília, DF: Diário Oficial da União, 11 novembro de 2009.

BROUGERE, G. A criança e a cultura lúdica. Revista Faculdade de Educação, São Paulo, v. 24, n. 2, p. 1-11, jul. 1998. Disponível em: http://www.scielo.br/scielo.php?script=sci_arttext\&pid=S0102-25551998000200007. Acesso em: 10 ago. 2021. 
BERWALDT, M. G. M.; NOGUEIRA, G. M

COHN, C. Antropologia da criança. Rio de Janeiro: Jorge Zahar, 2005.

CORSARO, W. Reprodução interpretativa e cultura de pares. In: MULLER, F.; CARVALHO, A. M. A. C. (org.). Teoria e prática na pesquisa com crianças: diálogos com William Corsaro. São Paulo: Cortez, 2009.

CORSARO, W. Sociologia da Infância. Porto Alegre: Artmed, 2011.

CUNHA, G. P. da. Ritos de morte na vida: a Ritualística Mortuária Pomerana em Santa Maria de Jetibá. Ciências da Religião: história e sociedade, São Paulo, v. 8, n. 1, p. 34-60, jan./jun. 2010.

GEERTZ, C. A interpretação das culturas. Rio de Janeiro: LTC, 2008.

HALL, S. Identidade cultural e diáspora. Revista do Patrimônio Histórico e Arte Nacional, n. 24, p. 68-75, 1997.

JACOB, J, K. A imigração alemã e a culinária pomerana no Espírito Santo. In: BELING, R. R. (org.). Terra dos bravos: imigração alemã no Brasil 180 anos. Santa Cruz do Sul: Gazeta Santa Cruz, p. 140-154, 2007.

MAIA, J. N. Concepções de criança, infância e educação dos professores de Educação Infantil. 2012. 135 f. Dissertação (Mestrado em Educação) - Universidade Católica Dom Bosco, Campo Grande, 2012.

MARLOW, S. L. Confessionalidade a toda prova: O Sínodo Evangélico Luterano do Brasil e a questão do Germanisno e do Nacional-Socialismo Alemão durante o Governo de Getúlio Vargas no Brasil. São Paulo: USP, 2013.

MULLER, F. Entrevista com Corsaro. Educação \& Sociedade (online), Campinas, v. 28, n. 98, p. 271-278, abril 2007. Disponível em: https://www.scielo.br/scielo.php?script=sci_arttext\&pid=S0101-73302007000100014. Acesso em: 10 ago. 2021.

NORÕES, K. C. De criança a estrangeira, de estrangeira a criança: mobilização social, agenda política e educação pública no município de São Paulo. 2018. 217 f. Tese (Doutorado em Educação) - Faculdade de Educação, Universidade Estadual de Campinas, Campinas. 2018.

OLIVEIRA, R. C. O trabalho do antropólogo. São Paulo: Editora UNESP, 2006.

RÖELKE, H, R. Descobrindo Raízes - Aspectos Geográficos, Históricos e Culturais da Pomerânia. Vitória: Universidade Federal do Espírito Santo. Secretaria de Produção e Difusão Cultural, 1996. 123 p. 
SARMENTO, M. J. Imaginário e culturas da infância. Cadernos de Educação, Pelotas, ano 12, n. 21, p. 51-70, jul./dez. 2003.

SARMENTO, M. J. Sociologia da infância: correntes e confluências. In: SARMENTO, M, J.; GOUVEA, M, C. Estudos da Infância: educação e práticas sociais. Rio de Janeiro: Vozes, 2008. p. 17-39.

SALOMONI, A. Lênin e a Revolução Russa. São Paulo: Ática, 1995.

SEIBEL, I. Imigrante no século do isolamento / 1870-1970. São Leopoldo: EST/PPG, 2010.

SEIBEL, I. Imigrante no século do isolamento / 1870-1970. São Leopoldo: EST/PPG, 2010.

SEYFERTH, G. A colonização alemã no Vale do Itajaí: um estudo de desenvolvimento econômico. Porto Alegre: Ed. Movimento, 1974.

SILLER, R. Infância, educação infantil, migrações. 2011. 261 p. Tese (Doutorado em Educação) - Programa de Pós-Graduação da Faculdade de Educação da Universidade Estadual de Campinas, Campinas, 2011.

TRESSMANN, I. Da Sala de Estar à Sala de Baile. Estudo Etnolinguístico de Comunidades Camponesas Pomeranas do Estado do Espírito Santo. (Tese de Doutorado) - Museu Nacional e Faculdade de Letras. Universidade Federal do Rio de Janeiro, Rio de Janeiro, 2005.

WHITAKER, D, C. Reforma Agrária e Meio Ambiente: Superando Preconceitos Contra o Rural. In: FERRANTE, V. L. B.; WHITAKER, D. C. A. (org.). Retratos de Assentamentos. Araraquara: Uniara. n. 12, 2009. p. 34-46.

WOORTMANN, E.; WOORTMANN, K. O Trabalho da Terra: A Lógica e a Simbólica da Lavoura Camponesa. Brasília: Editora Universidade de Brasília, 1997.

Myrna Gower Madia Berwaldi: Mestranda no Programa de Pós-graduação em Educação da Universidade Federal do Rio Grande (FURG). Graduada em Pedagogia pela mesma universidade. Pesquisadora do Grupo de Estudo e Pesquisa em Alfabetização e Letramento - GEALI.

Orcid: https://orcid.org/0000-0003-1165-810X

E-mail: myrnaberwaldt@yahoo.com.br 
BERWALDT, M. G. M.; NOGUEIRA, G. M

Gabriela Medeiros Nogueira: Doutora em Educação pela Universidade Federal de Pelotas - UFPEL. Realizou Pós-doutorado na University of Illinois at Urbana-Champaign - UIUC, em 2016 e na University of Canterbury - UC na Nova Zelândia, em 2019. Professora no Instituto de Educação da Universidade Federal do Rio Grande (FURG) e no Programa de Pós-graduação em Educação da mesma universidade. Líder do Grupo de Estudo e Pesquisa em Alfabetização e letramento - GEALI, é pesquisadora no Núcleo de Estudo e Pesquisa em Educação da Infância - NEPE/FURG e no Grupo de pesquisa em História da Alfabetização, Leitura, Escrita e dos Livros Escolares - HISALES/UFPEL. Orcid: https://orcid.org/0000-0002-6985-064X

E-mail: gabynogueira@me.com

Este periódico utiliza a licença Creative Commons Attribution 3.0, para periódicos de acesso aberto (Open Archives Initiative - OAI).

Inter-Ação, Goiânia, v.46, n.2, p. 556-576, maio/ago. 2021. Disponível em: <http://dx.doi.org/10.5216/ia.v46i2.67811>. 